Reprinted from Holcomb-McCoy, C. \& Myers, J. E. (1999). Multicultural competence and counselor training: A national survey. Journal of Counseling and Development, 77(3), 294-302.

The American Counseling Association. Reprinted with permission. No further reproduction authorized without written permission from the American Counseling Association: http://www.counseling.org/

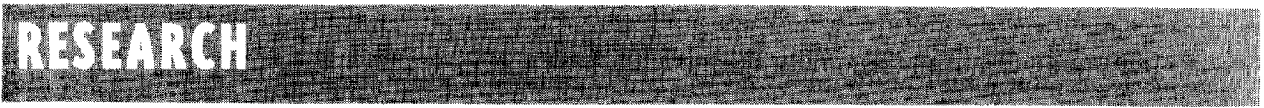

\title{
Multicultural Competence and Counselor Training: A National Survey
}

\author{
Cheryl C. Holcomb-McCoy and Jane E. Myers
}

The extent to which practicing professional counselors perceive themselves as multiculturally competent and the basis for their training experiences in multicultural counseling have not been determined. This article reports the results of a survey on practicing professional counselors' perceptions of their multicultural competence and the nature of their pre-and in-service professional preparation in this area. There was no significant difference in self-perceived multicultural competence between graduates of Council for Accreditation of Counseling and Related Educational Programs (CACREP) accredited and nonaccredited programs. However, ethnicity was related to higher levels of perceived multicultural competence.

\section{A}

merican society today is more multilingual, multiethnic, and multicultural than at any other time in its history, and is expected to be even more so in the future (Aponte \& Clifford, 1993; Sue, 1991; U. S. Bureau of the Census, 1992). Dramatic changes in the ethnic composition of the United States have had a significant impact not only on the counseling process, but also on the dynamics of the counselor/client relationship (Atkinson, Thompson, \& Grant, 1993; Whitfield, 1994). As a consequence, counselor educators as well as practicing counseling professionals have realized the necessity of incorporating multicultural content and training into both pre- and in-service training for preparing what have come to be known as "multiculturally competent counselors" (Atkinson, Morten, \& Sue, 1989, Council for Accreditation of Counseling and Related Educational Programs [CACREP], 1994; Ponterotto \& Casas, 1987). Multiculturally competent counselors are professionals who possess the necessary skills to work effectively with clients from various cultural/ethnic backgrounds (Abernethy, 1995; Ponterotto \& Casas, 1987; Sue, Arredondo, \& McDavis, 1992). Over the past two decades, the literature regarding multicultural counseling competence has focused on three main areas: (a) awareness of one's own personal worldviews and how one is the product of cultural conditioning, (b) knowledge of the worldviews of culturally different clients, and (c) skills necessary for work with culturally different clients (Corvin \& Wiggins, 1989; D'Andrea, Daniels, \& Heck, 1992; Sue et al., 1992). It is presumed that counselors who acquire competence in these three areas will possess the characteristics and understand the strategies necessary to effectively counsel culturally different clients (Pedersen \& Ivey, 1993; Ponterotto, Rieger, Barrett, \& Sparks, 1994; Sabnani, Ponterotto, \& Borodovsky, 1991). The three areas of multicultural competence listed earlier were used by the Association for Multicultural Counseling and Development (AMCD) Professional Standards Committee as the basis for developing a set of Multicultural Counseling Competencies. The competencies are intended to guide "interpersonal counseling grounded in the context of culture, ethnicity and race" (Arredondo et al., 1996). In developing the competencies, the authors defined multicultural counseling as counseling when the participants differ as a result of their varying racial and ethnic backgrounds (i.e., African/Black, Hispanic/Latino, Asian, Caucasian/European, and Native American or indigenous groups). Recently, as a result of continued research, explanatory statements were added to the Competencies to address specific behaviors such as the ability to identify one's culture(s), recognize stereotyped reactions to culturally dif-

Cheryl C.Holcomb-McCoy is an assistant professor in the Department of Counseling and Personnel Services at the University of Maryland at College Park. Jane E. Myers is a professor in the Counseling and Educational Development Department at the University of North Carolina at Greensboro. Correspondence regarding this article should be sent to Cheryl C. Holcomb-McCoy, University of Maryland, 3214 Benjamin Building, College Park, MD 20742 (e-mail: ch193@umail.umd.edu). 
ferent persons, articulate cultural differences between ethnic groups, and other activities that demonstrate the attainment of multicultural competence (D. Locke, personal communication, October 25, 1995). According to Arredondo et al. (1996), the explanatory statements are "examples and anecdotes that give life to the competencies" (p. 9). Both the competencies and the explanatory statements are intended to be the basis for preparation of multiculturally competent counselors.

In addition to the development of multicultural counseling competencies, various models and methods of training have been designed to develop and ensure counselors' multicultural competence (Chambers, Lewis, \& Kerezsi, 1995; D'Andrea et al., 1992; Ibrahim, Stadler, Arredondo, \& McFadden, 1986). Heath, Neimeyer, and Pedersen (1988) predicted that the methods and focus of training would vary from program to program. At the present time, this seems to be true. For example, Pedersen's (1988) Triad Model emphasizes the skill development of counselor trainees. In contrast, Mio's (1989) perspective on training focuses on actual experience with culturally different clients. Ivey and Nwachuku (1991) proposed integrating an Afrocentric method of helping with training, and Carney and Kahn's (1984) method of multicultural training links counselor training with the ongoing process of counselor development. Counselor educators are addressing the challenge of training counselors by offering courses that deal specifically with multicultural issues (Herr, 1989; McDavis \& Parker, 1977). In fact, from 1989 to 1991, multicultural counseling courses were the most frequently added new courses in counselor preparation programs (Hollis \& Wantz, 1990 ). Although many preparation programs have created and incorporated multicultural courses, fewer programs have infused core counseling courses with multicultural content (D'Andrea et al., 1992). Copeland (1982) suggested that the infusion or integration model of training was the most desirable model because of its flexibility in meeting all trainees' needs. D' Andrea et al, also cited the integration/infusion model as the preferred model of training to prepare culturally competent counselors. However, D'Andrea et al. stated that it is the most difficult model to use, because it entails cooperation from all individuals involved in the counselor education program. In addition, ongoing evaluation of the preparation program and continuing modification of components of the program, based on feedback from students and supervisors, makes this a more complex model to operationalize. To further ensure the multicultural competence of counselors, professional credentialing bodies, in particular CACREP, have incorporated multicultural issues into their standards. In the 1994 CACREP standards, curricular experiences in multicultural counseling are specifically incorporated into the Social and Cultural Foundations core area. Multicultural perspectives are also included in three other core areas of the standards: Helping Relationships, Lifestyle and Career Development, and Appraisal. In addition to requiring the integration of multiculturalism into core subject areas, the CACREP standards require that counselor education programs have diverse faculty and student representation along with practicum and internship placements that provide clinical experiences with culturally different clients. As of October 1996, there were 115 institutions with CACREP accreditation (C. Bobby, personal communication, April 14, 1997). Although there are more programs becoming accredited by CACREP and adhering to the CACREP standards, additional information is needed regarding the contribution of the CACREP multicultural training standards to the development of multicultural counseling competence in professional counseling. Whereas the counselor education literature lacks data on the status and adequacy of multicultural training in CACREP-accredited programs, the counseling psychology literature yields valuable information regarding multicultural training in American Psychological Association (APA) accredited programs. For instance, Hills and Strozier (1992) surveyed 61 APAaccredited counseling psychology programs and found that $87 \%$ offered at least one course on multicultural issues. Although these results are encouraging, Hills and Strozier's survey provided no information as to whether the results are a response to accreditation pressure or the result of a genuine interest in and commitment to multicultural training in counseling psychology programs. In a recent study that focused on the competence of graduates (Allison, Crawford, Echemendia, Robinson, \& Knepp, 1994), counseling psychologists reported low levels of competence when providing services to ethnic minority clients. Nevertheless, more than $50 \%$ of the respondents indicated high feelings of competence in providing services to European Americans, women, and economically disadvantaged individuals. Similar studies with graduates of counselor education programs have not been conducted. The primary purpose of the present study was to assess professional counselors' perceptions of their multicultural competence and training. Using the Multicultural Competencies developed by the AMCD, five research questions were posed:

1. What factors constitute the multicultural counseling competencies?

2. To what extent do professional counselors perceive themselves to be multiculturally competent based on these factors?

3. Are there differences between the self-perceived multicultural competence of professional counselors who graduated from counseling programs accredited by CACREP and those who graduated from nonCACREP-accredited programs?

4. What are counselors' perceptions of the adequacy of training they have received in multicultural counseling?

5. Is there a relationship between selected demographic factors (e.g., age, gender, ethnicity) and multicultural counseling competence?

Regarding the fifth question, there is some evidence that demographic characteristics influence the multicultural competence of counselors. For example, gender (Carter, 
1990), educational level (Sabnani et al., 1991), and age (Sodowsky, Taffe, \& Gutkin, 1991) have been found to be related to multicultural competence. In addition, contact with culturally different persons has been shown to be positively correlated with higher levels of self-reported multicultural competence (Sodowsky et al., 1991).

\section{METHOD}

\section{Participants}

A stratified sample of 500 professional counselors was drawn from the membership of the American Counseling Association (ACA, $N=55,281$ ). The sample was stratified both by ethnic background and recency of graduation. To ensure an adequate sample size of ethnic minority counselors to permit valid comparisons based on ethnicity, an attempt was made to oversample ethnic minorities. This was accomplished by recruiting half of the sample from the membership of AMCD $(n=250)$, the division of ACA that includes the most ethnic minority members. Furthermore, in an attempt to ensure an adequate sample of recent graduates of CACREP programs, one half of the non-AMCD $(n=125)$ and AMCD members $(n=125)$ were recruited from those ACA members who joined after 1992. A total of 151 counselors (30\%) responded to the survey. Most of the responding counselors had a master's degree (79\%), and $15 \%$ had doctoral degrees. All four ACA regional locations were represented, with $21 \%$ from the Northeast, $27 \%$ from the Midwest, $32 \%$ from the South and, $16 \%$ from the West. With respect to work setting, $31 \%$ worked in schools, $24 \%$ were employed in mental health agencies, $17 \%$ worked on college and university campuses, and the remaining $12 \%$ indicated that their work setting was best described as business/industry, government, corrections facility, or other. In comparison, the total ACA membership consists of counselors who work in schools (25\%), mental health agencies $(17 \%)$, private practice (31\%), with the remainder working in either colleges, government agencies, or business settings. Over half of the counselors $(68 \%)$ were female, and $33 \%$ were between the ages of 45 and 54. ACA's membership, in comparison, is $71 \%$ female and $29 \%$ male. Twenty-seven percent of the counselors in the sample were in the 35-to- 44 age group and $24 \%$ were in the 25 -to-34 age group. As a result of oversampling members in AMCD, the proportion of ethnic minorities (e.g., AfricanAmerican, Asian) in the final sample was $30 \%$, not including those respondents who identified themselves as other. Sixty-six percent of the respondents were of European/White descent, 19\% were of African/ Black descent, and $6 \%$ were of Latino/Hispanic descent. A small percentage of the respondents (5\%) indicated an Asian or Native American background, and 4\% marked other. The actual representation of ethnic minorities in ACA is estimated at $7 \%$. However, the membership of AMCD includes $49 \%$ ethnic minority membership. Of the 151 respondents, $51 \%$ graduated between the years 1990 and $1995,28 \%$ graduated between 1980 and $1989,15 \%$ between 1970 and 1979 , and $6 \%$ graduated before 1970 . Thirty percent of the respondents graduated from an entry-level counseling program in or after 1994. Of those respondents, $55 \%$ graduated from CACREP-accredited programs. Fifty-seven percent of the professional counselors in the total sample, however, graduated from non-CACREP-accredited programs.

\section{Variables}

A 61 -item survey was developed to determine professional counselors' perceptions of their multicultural counseling competence and the adequacy of their training. After the development of the items, feedback on the content and format of the survey was solicited from several persons noted for their expertise in multicultural issues, as well as from 17 pilot study participants, all of whom were professional counselors. As a result of their recommendations, several format and wording changes were made to the initial survey. The items on the revised survey were divided into six areas: (a) Multicultural Counseling Curriculum in EntryLevel Graduate Program, (b) Faculty and Students in Entry-Level Program, (c) Multicultural Clinical Experiences in Entry-Level Program, (d) Postgraduate Multicultural Training and Experience, (e) Demographic Information, and (f) Self-Assessment of Multicultural Counseling Competence and Training. For Parts I through 4, respondents were asked to indicate information regarding their entry-level and postgraduate multicultural counseling training experiences. Part 5 included demographic information such as gender, age, ethnic background, year of graduation with highest degree, and accreditation status of graduate counseling program.

Part 6 consisted of 32 behaviorally based statements, based on the Multicultural Counseling Competencies and Explanatory Statements (e.g., "I can discuss how culture affects the help-seeking behaviors of clients.") Respondents were asked to assess and report on three areas for each statement: selfperceived competence, adequacy of training received concerning this specific competency, and what types of training had been received. Competence was rated using a 4 -point Likerttype scale, $4=$ extremely competent, $3=$ competent, $2=$ somewhat competent, and $\mathrm{l}=$ not competent. To assess the adequacy of training they received, respondents used the following 4point Likert-type scale: $4=$ more than adequate training received, 3 = adequate training received, 2 = less than adequate training received, and $l=$ no training received. To assess where their training had been received, respondents chose one or more areas from the following options: multicultural course(s) in entry-level counseling program, core counseling courses infused with multicultural content, informal professional development activities (e.g., independent readings, life experiences), formal professional development activities (e.g., workshops, seminars), and advanced degree programs. (See the Appendix for a list of the survey items.)

\section{Procedure}

The 61-item Multicultural Counseling Competence and Training Survey (MCCTS) was mailed to the 500 prospec- 
tive respondents along with a cover letter explaining the purpose of the study and instructions for completion of the instrument. A self-addressed, stamped envelope was included to encourage return of the surveys. No follow-up letters or questionnaires were mailed due to the lack of additional funds.

\section{RESULTS}

\section{Question 1: Factors of Multicultural Competence}

Results were analyzed using the SPSS statistical package. A principle components factor analysis was performed to investigate the underlying factors of the items in Part 6 of the survey. Frequencies, means, and standard deviations were computed for all items. The internal consistency reliability of the factor scores were calculated. One-way analyses of variance were computed using selected demographic information, individual items, and the five-factor scores that emerged from the data analyses.

Five factors were extracted using a principal components factor analysis with an oblimin rotation. Minimum eigenvalues were used to determine the number of factors to extract in the final solution and a minimum factor loading of . 35 was required for an item to be interpreted as part of a factor. The factor analysis resulted in the identification of five factors that explained $63 \%$ of the variance of the competence items. Table 1 shows the factor loading of the five factors as well as their eigenvalues and the percent of variance explained by each factor. In addition, alpha coefficients for each factor are shown in this table. The alpha coefficients ranged from .66 to .92 , with the highest internal consistency resulting for Factors 1, 2, and 5, and the lowest for Factor 4. This factor also included the lowest number of items loading on the factor $(N=2)$.

A review of the items associated with each factor resulted in the identification of Factor 1 as Knowledge of multicultural issues (e.g., "I can discuss family therapy from a cultural/ethnic perspective"). Factor 2 was defined as Awareness (e.g. " I am able to discuss how my culture has influenced the way I think"). Factor 3 included items that asked for definitions of important multicultural counseling terms (e.g., "I can define prejudice"), and thus was defined as Definitions. Factor 4, defined as Racial Identity Development, included the only two items on the survey that addressed this issue (e.g., "I can discuss the counseling implications for at least two models of minority identity development"). Factor 5, Skills, included skill-based items (e.g., "I verbally communicate my acceptance of culturally different clients").

\section{Question 2: Self-Perceived Multicultural Competence}

To examine professional counselors' perceptions of their multicultural competence, means and standard deviations were computed for the factor scores. The ratings of competence for each factor, as shown in Table 2, were between "competent" and "extremely competent." Overall, the respondents perceived themselves to be most competent on

\section{TABLE 1}

Factor Loadings of Competence Items and Internal Consistency of Factors

\begin{tabular}{|c|c|c|c|c|}
\hline Factor & $\begin{array}{l}\text { Items With } \\
\text { Highest } \\
\text { Loadings }\end{array}$ & $\begin{array}{l}\text { Factor } \\
\text { Loadings }\end{array}$ & $\underset{\text { Coefficients }}{\alpha}$ & $\begin{array}{l}\text { Eigenvalue/ } \\
\text { Variance (\%) }\end{array}$ \\
\hline \multirow[t]{16}{*}{1} & 16 & .38 & \multirow[t]{16}{*}{.92} & \multirow[t]{16}{*}{$14.97 / 47$} \\
\hline & 17 & 69 & & \\
\hline & 18 & .77 & & \\
\hline & 20 & .77 & & \\
\hline & 21 & .81 & & \\
\hline & 22 & .84 & & \\
\hline & 23 & .71 & & \\
\hline & 24 & .74 & & \\
\hline & 25 & .54 & & \\
\hline & 26 & .71 & & \\
\hline & 27 & .74 & & \\
\hline & 28 & .64 & & \\
\hline & 29 & .60 & & \\
\hline & 30 & .52 & & \\
\hline & 31 & .59 & & \\
\hline & 32 & .54 & & \\
\hline \multirow[t]{5}{*}{2} & 1 & .65 & \multirow[t]{5}{*}{.92} & \multirow[t]{5}{*}{$2.37 / 7$} \\
\hline & 2 & .75 & & \\
\hline & 3 & .86 & & \\
\hline & 4 & .44 & & \\
\hline & 7 & .46 & & \\
\hline \multirow[t]{4}{*}{3} & 9 & -87 & \multirow[t]{4}{*}{.79} & \multirow[t]{4}{*}{$1.14 / 4$} \\
\hline & 10 & -.95 & & \\
\hline & 11 & -.82 & & \\
\hline & 12 & -.79 & & \\
\hline \multirow[t]{2}{*}{4} & 19 & .42 & \multirow[t]{2}{*}{.66} & \multirow[t]{2}{*}{$.92 / 3$} \\
\hline & $B$ & .48 & & \\
\hline \multirow[t]{3}{*}{5} & 5 & -.46 & \multirow[t]{3}{*}{.91} & \multirow[t]{3}{*}{$.59 / 2$} \\
\hline & 6 & -.35 & & \\
\hline & 15 & -31 & & \\
\hline
\end{tabular}

the definitions and awareness factors (Factors 3 and 2). In contrast, the respondents perceived themselves to be the least competent on the racial identity and knowledge dimensions (Factors 4 and 1 ).

\section{Question 3: Perceptions of Multicultural Competence of CACREP-Accredited and Non-CACREP-Accredited Program Graduates}

To compare the differences between the CACREP and nonCACREP graduates' self-perceived multicultural competence, a multivariate analysis of variance was used. The dependent variables were the items identified for each factor. The independent variable was the variable CACREP with two levels: CACREP graduate and non-CACREP graduate. No significant differences were found $(p<.05)$. The results are presented in Table 2 .

\section{Question 4: Counselors' Perceptions of Adequacy of Their Multicultural Training}

The means and standard deviations for the five factors for all respondents on training ranged between "adequate training received" and "rnore than adequate training received." 
TABLE 2

Means and Standard Devlatlons for CACREP and Non-CACREP Graduates on Multicultural Competence and
on Adequacy of Training

\begin{tabular}{|c|c|c|c|c|c|c|c|c|c|}
\hline \multirow[b]{2}{*}{ Factor } & \multicolumn{2}{|c|}{ CACREP } & \multicolumn{2}{|c|}{ Non-CACREP } & \multicolumn{2}{|c|}{ Total } & \multirow[b]{2}{*}{$d f$} & \multirow[b]{2}{*}{$\boldsymbol{F}$} & \multirow[b]{2}{*}{$\boldsymbol{p}$} \\
\hline & $M$ & $\mathbf{S D}$ & $M$ & SD & $M$ & $S D$ & & & \\
\hline \multicolumn{10}{|c|}{ Multiculłural Competence } \\
\hline $\begin{array}{l}\text { 1. Knowledge } \\
\text { 2. Awareness } \\
\text { 3. Definition of Terms } \\
\text { 4. Racial Identity } \\
\text { 5. Skills }\end{array}$ & $\begin{array}{l}2.61 \\
3.36 \\
3.36 \\
2.29 \\
3.30\end{array}$ & $\begin{array}{l}1.39 \\
1.64 \\
0.66 \\
0.99 \\
1.69\end{array}$ & $\begin{array}{l}2.75 \\
3.40 \\
3.64 \\
2.38 \\
3.24\end{array}$ & $\begin{array}{l}1.36 \\
0.64 \\
1.56 \\
1.23 \\
0.77\end{array}$ & $\begin{array}{l}2.70 \\
3.38 \\
3.43 \\
2.33 \\
3.27\end{array}$ & $\begin{array}{l}0.91 \\
0.67 \\
0.64 \\
1.01 \\
0.73\end{array}$ & $\begin{array}{r}16,27 \\
5,37 \\
4,40 \\
2,42 \\
5,35\end{array}$ & $\begin{array}{l}0.93 \\
1.56 \\
0.55 \\
2.74 \\
0.57\end{array}$ & $\begin{array}{l}.548 \\
.197 \\
.696 \\
.076 \\
.723\end{array}$ \\
\hline \multicolumn{10}{|c|}{ Adequacy of Training } \\
\hline $\begin{array}{l}\text { 1. Knowledge } \\
\text { 2. Awareness } \\
\text { 3. Definition of Terms } \\
\text { 4. Racial Identity } \\
\text { 5. Skills }\end{array}$ & $\begin{array}{l}2.31 \\
2.49 \\
2.81 \\
2.26 \\
2.45\end{array}$ & $\begin{array}{l}0.98 \\
1.08 \\
1.07 \\
1.02 \\
1.02\end{array}$ & $\begin{array}{l}2.37 \\
2.60 \\
2.84 \\
2.08 \\
2.54\end{array}$ & $\begin{array}{l}0.94 \\
1.03 \\
0.93 \\
1.02 \\
0.94\end{array}$ & $\begin{array}{l}2.38 \\
2.55 \\
2.83 \\
2.17 \\
2.50\end{array}$ & $\begin{array}{l}0.92 \\
1.05 \\
0.98 \\
1.02 \\
0.99\end{array}$ & $\begin{array}{r}16,27 \\
5,37 \\
4,40 \\
2,42 \\
5,35\end{array}$ & $\begin{array}{l}1.76 \\
1.84 \\
0.24 \\
1.61 \\
0.44\end{array}$ & $\begin{array}{l}.037 \\
.107 \\
.917 \\
.203 \\
.726\end{array}$ \\
\hline
\end{tabular}

Note. CACREP = Council for Accreditation of Counseling and Related Educational Programs.

To determine differences between CACREP graduates' and non-CACREP graduates' perceptions of their multicultural training, a multivariate analysis of variance was used. The items identified for each factor served as the dependent variables. The independent variable was the variable CACREP with two levels: one, CACREP graduate and two, non-CACREP graduate. A significant difference was found between the CACREP and non-CACREP graduates' perception of training on the knowledge factor. The remaining four factors showed no significant differences between the two sets of graduates (see Table 2).

\section{Question 5: The Relationship Between Selected Demographics and Multicultural Competence}

A series of multivariate analyses of variance was used to determine if professional counselors' self-perceived multicultural competence could be explained by selected demographic variables. The demographic variables examined in this study were professional counselors' work setting, educational level, ethnicity, gender, and age. The competence items associated with each factor were dependent variables, and the selected demographic items served as the independent variable. The effect of ethnicity was the only demographic variable that was statistically significant and influenced the knowledge, awareness, racial identity, and skill factors of multicultural counseling competence, $F(16,48)=2.09, p<.03 ; F(5,60)=2.89, p<$ $.03 ; F(2,65)=4.04, p<.03 ; F(5,58)=5.21, p<.01$; respectively. The definition of terms factor was the only factor that was not influenced by ethnicity. (Author Note: If readers wish to review all of the statistics related to this question, please contact the senior author.)

\section{Post Hoc Analyses}

A final set of analyses was used to test differences among the factors by the characteristics of "taking a multicultural counseling course." Those respondents who had taken a multicultural counseling course $(46 \%)$ had significantly higher levels of self-perceived multicultural counseling competence on the knowledge and racial identity dimensions, $F(16,125)=1.98, p=.020 ; F(2,146)=3.68$. $p=.028$; respectively. For exploratory purposes, another analysis was undertaken to determine if there were significant interaction effects between ethnicity and "taking a multicultural counseling course." Although the effect of ethnicity was statistically significant and influenced all of the factors, overall there were no significant interaction effects between ethnicity and "taking a multicultural course."

\section{DISCUSSION}

Several potential limitations are important to consider when interpreting the results of this study. Perhaps the primary limitation of this study is its self-report nature. As with any type of survey, responses to the MCCTS may reflect respondents' desire to seem competent rather than otherwise. A second potential limitation concerns the high percentages of ethnic minority persons and recent graduates included in the sample. Although the sampling procedures were necessary to assure adequate numbers of ethnic minority persons for valid analyses, the representativeness of ACA membership is a possible concern. However, the results can be generalized to ACA's ethnic minority membership and the respondents were representative of all ACA geographic re- 
gions, work settings, gender, and work positions. A final limitation is the low return rate $(30 \%)$ of the survey. As mentioned previously, lack of additional funding prohibited the researchers from doing a follow-up mailing. Although these concerns limit the generalizability of the results, the data suggest a number of significant issues for counselor preparation and counseling research. This study revealed that five factors-awareness, knowledge, definitions, racial identity development, and skills-constitute the Multicultural Competencies developed by AMCD. This finding suggests that the Multicultural Competencies comprise more than the three dimensions proposed in the literature. Moreover, the results imply that there could be a possible limitation in current multicultural training because most methods of multicultural training focus on a combination of the three proposed dimensions of multicultural competence-awareness, knowledge, and skills.

The results of this study suggest that professional counselors, as a group, perceive themselves to be multiculturally competent. Professional counselors believe that they are most competent on the awareness, skills, and definitions areas of competence, and they perceive themselves to be less competent on the knowledge and racial identity dimensions. The differences between the levels of competence on specific dimensions suggest that professional counselors are less knowledgeable about their clients' cultures and most knowledgeable about their own personal worldview. This is surprising, because it has been noted that most training strategies focus on "knowing that" (i.e., knowledge) cultural differences exist rather than "knowing how"(i.e., skills) to conduct effective counseling sessions with diverse clients (Johnson, 1987). In addition, the low ratings of respondents regarding racial identity development might reflect the rather recent emergence of, and consequent unfamiliarity with, racial identity theories in the counseling profession.

Regarding the adequacy of training, the finding that they perceive their multicultural counseling training to have been less than adequate seems inconsistent with the finding that professional counselors perceive themselves to be multiculturally competent. One might then ask, Where and when do counselors acquire their multicultural competence? Perhaps multicultural competence evolves as a result of cross-cultural experiences or postdegree training. The results of this study seem to suggest that counselors are acquiring their multicultural competence through postdegree work with culturally different clients rather than through graduate course work. Clearly, this relationship between counselor development and multicultural competence is an area for further exploration.

In addition to the mystery of where training occurs, it seems that professional counselors received their most adequate training in defining terms and cultural awareness. Lower ratings were indicated on the items reflective of the knowledge and racial identity dimensions. This finding may be a result of two things: one, that counselor trainers are not addressing these dimensions of multicultural compe- tence directly; and two, that counselors feel less competent with the content of these areas and thus, perceive their training to be less than adequate. The knowledge and racial identity dimensions also received the lowest competence ratings, suggesting that these are not only areas that necessitate better training, but also areas in which counselors feel the least competent.

A notable finding of this study was the effect that ethnicity had on four dimensions of multicultural competence. In general, self-perceived multicultural competence can be explained by whether or not a counselor is a member of an ethnic minority group. This finding is interesting in that ethnicity seems to explain most of the variance in multicultural competence among the professional counselors sampled. Previous researchers (i.e., Sodowsky et al., 1991) have observed that persons in daily contact with culturally different persons are more culturally competent. Therefore, perhaps by merely being a member of an ethnic minority group and experiencing daily contact with White Americans, an ethnic minority person experiences multicultural training in vivo or through life experiences (Lee \& Richardson, 1991).

Finally, the results indicate that there are no differences between the self-perceived multicultural competence of counselors who graduated from CACREP-accredited programs and those who did not. Several conclusions can be drawn from this find ing. First, because the 1994 CACREP standards have only been in effect for 3 years, these results could imply that CACREP programs have not had sufficient time to fully implement the multicultural components of the 1994 standards. Second, these findings could indicate that the CACREP standards and AMCD's Multicultural Competencies are not linked and, thus, address different dimensions of multicultural competence. This is evidenced further by the contrasting definitions of multiculturalism that each organization supports. Whereas CACREP proposes a very broad definition of multiculturalism that includes differences pertaining to gender, age, religion, and social groups, AMCD endorses a definition of multiculturalism that relates specifically to ethnic/racial groups.

\section{IMPLICATIONS}

Several implications for counselor preparation may be drawn from the results of this study. First, the findings seem to suggest that the most adequate training is evidenced in the definitions dimension. In light of these results, counselor educators should be cognizant of including training in their curriculum that focuses on all of the dimensions of multicultural competence revealed in this study. Furthermore, counselor educators should incorporate and provide for in vivo learning experiences, because it is probable that these experiences are related to the higher self-competence ratings of ethnic minority persons. Second, based on the results of this study, counselor educators in CACREP programs should assess whether their programs are actively and appropriately meeting the prescribed standards. More- 
over, the differences between CACREP and AMCD's perspective on multiculturalism should be clarified so that there is consistency between the two organizations' expectations of multiculturally competent counselors as well as training practices.

Third, the results of this study suggest that taking a multicultural course significantly influences professional counselors' self-perceived multicultural knowledge and racial identity competence. Counselor educators, therefore, should begin or continue to encourage the development of courses that focus on multicultural issues specifically pertaining to knowledge regarding other cultural groups and racial identity development, because these dimensions received the lowest competence mean ratings. More important, however, counselor trainers should develop basic and advanced multicultural courses that encompass all of the dimensions revealed in this study.

Because the current study indicated that practicing professional counselors perceive their training to be less than adequate, finding adequate and effective training is an important issue. It is essential that counseling settings provide counselors with the support needed to attend and participate in effective multicultural training experiences. Support might include travel funds and leave for counselors who want to participate in training outside of their work setting.

There are several implications for counseling research that are evident from this study. First, a replication of this study should be implemented with a larger sample to confirm our findings. Because the sample size in this study was relatively small compared with the total population of ACA, a larger sample could reveal even more significant results.

Second, qualitative research is needed to further explore the self-perceived multicultural competence of professional counselors in multicultural interactions and counseling settings. Interviews would be a useful tool for understanding the significance of ethnicity and multicultural competence. Furthermore, additional information regarding the types of training experiences that influence self-perceived multicultural competence is greatly needed.

Third, further studies examining the relationship between AMCD's Multicultural Competencies and the CACREP standards is needed. Additional research designed to determine if the competencies are based on one general underlying factor or several factors, as found in this study, would be advantageous.

Fourth, it would be useful to conduct this study in the future when the CACREP Standards and the Multicultural Competencies have been adopted by more programs and when there are more graduates from CACREP-accredited programs. A later study could possibly determine if there is a significant difference between the ratings of CACREP graduates versus non-CACREP graduates.

Fifth, research regarding the differences between the selfperceived multicultural competence of varying ethnic groups would be useful. For example, comparing the self-perceived multicultural competence of African American counselors with that of Hispanic/Latino counselors would yield perti- nent information regarding the effect of ethnicity on multicultural competence. Similarly, future research could examine the multicultural competence of professional counselors when counseling clients of specific ethnic/cultural groups.

\section{CONCLUSION}

If the counseling profession is to provide effective services to a rapidly changing and diverse society, ongoing effective multicultural training and the evolution of culturally competent counselors are a necessity. Counselor training programs, therefore, must provide appropriate multicultural training experiences that enrich the multicultural competence of their trainees. In this study, we have sought to determine and identify significant relationships between counselor training, multicultural competence, and demographic characteristics of professional counselors. Although further research is needed to confirm and further explain the nature of these relationships, the findings of this study do imply that counselor educators and researchers could benefit from attending to these pertinent issues.

\section{REFERENCES}

Abernethy, A. D. (1995). Managing racial anger: A cultural skill in cultural competence. Joumal of Muficultural Counseling and Development, 23, 96-102.

Allison, K. W. Crawford, I., Echemendia, R., Robinson, L., \& Knepp, D. (1994). Human diversity and professional competence: Training in clinical and counseling psychology revisited. American Psychologist, 49, 792-796.

Aponte, I. F. \& Clifford, J. P. (1993). Incorporating ethnically diverse content and training into predominately White graduate and professional programs: Dealing with inertia and resistance. New York: Columbia University Teacher's College. (ERIC Document Reproduction Service No. ED 376235 )

Arredondo, P., Toporek, R., Brown, S., Jones, J., Locke, D. C., Sanchez, J.,

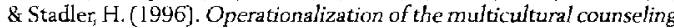
competencies. Alexandria, VA: Association for Multicultural Counseling and Development.

Atkinson, D. R., Morten, G. \& Sue, D. W. (1989). Counseling American minorities: A cross-cultural perspective (3rd ed.). Dubuque, IA: Brown.

Atkinson, D. R., Thompson, C. E., \& Grant, S. K. (1993). A three-dimensional model for counscling racial/ethnic minorities. The Counseling $P_{\text {sychologist, }}$ $21,257-277$

Carney, C. G., \& Kahn, K. B. (1984). Building competencies for effective cross-cultural counseling: $A$ developmental view. The Counseling $P$ sychologist, 12,111-119.

Carter, R. T. (1990). The relationship between racism and racial identity among White Americans: An exploratory investigation. Journal of Counseling \& Development, 69, 46-50.

Chambers, T., Lewis, J., \& Kerczsi, P. (1995). African American faculty and White American students: Cross-cultural pedagogy in counselor preparation programs. The Counscling Psychologist, 23, 43-62.

Copeland, E. I. (1982). Minority populations and traditional counseling prograns: Some alternatives Counzelor Education and Supervision, 19, 187-193.

Corvin, S. A., \& Wiggins, F. (1989) An antiracism training model for White professionals. Journal of Multicultural Counseling and Development, $17,105-114$.

Council for Accreditation of Counseling and Related Educational Programs. (1994). Accreditation and procedures manual and application. Alexandria, VA: Author

Council for Accreditation of Counseling and Related Educational Programs. (1995, October). CACREP Connection. Alexandria, VA: Author.

D'Andrea, M, Daniels, J., \& Heck, R. (1992). Evaluating the impact of multicultural counseling training. Joumal of Counseling \& Development, 70, 143-150. 
Heath, A. E., Neimeyer, G. J., \& Pedersen, P. B. (1988). The future of cross-cultural counseling: A delphi poll. Journal of Counseling and Development, 67, 27-30.

Herr, E. L. (1989). Counseling in a dynamic society: Opportunities and challenges. Alexandria, VA: American Association for Counseling and Development.

Hills, H. I., \& Strozier, A. L. (1992). Multicultural training in APA-approved counseling psychology programs: A survey. Professional Psychology: Research and Practice, 23, 43-51.

Hollis, J., \& Wantz, R. (1990). Counselor Preparation 1990-1993 (7th ed.). Muncie, IN: Accelerated Development.

Ibrahim, F. A., Stadler, H. A., Arredondo, P., \& McFadden, J. (1986, April). Status of human rights issues in counselor education: A national survey. Paper presented at the meeting of the American Association for Counseling and Development, Los Angeles, CA.

Ivey, A. E., \& Nwachuku, U. (1991). Culture specific counseling: An alternative approach. Journal of Counseling \& Development, 70, 106-111.

Johnson, S. D. (1987). Knowing that versus knowing how:'Toward achieving expertise through multicultural training for counseling. The Counseling Psychologist, 15, 320-331

Lee, C. C., \& Richardson, B. L. (1991). Promise and pitfalls of multicultural counseling. In C. C. Lee \& B. I. Richardson (Eds.), Multicultural issues in counseling: New approaches to diversity [pp 3-9). Alexandria, VA: The American Association for Counseling and Development.

McDavis, R. J., \& Parker, M. (1977). A course on counseling ethnic minorities: A model. Counselor Education and Supervision, I7, 146-149.

Mic, J. S. (1989). Experiential involvement as an adjunct to teaching cultural sensitivity. Journal of Multicultural Counseling and Development, 17, 38-46

Pedersen, P. B. (1988). A handbook for developing multicultural awareness. Alexandria, VA: American Association for Counseling and Development.

Pedersen, P. B. \& Ivey, A. (1993). Culture-centered counseling and interviewing skills: A practical guide. Westport, CT: Praeger Publishers.

Ponterotto, J. G., \& Casas, J. M. (1987). In search of multicultural competence within counselor education programs. Journal of Counseling and Development, $65,430-434$.

Ponterotto, J. G., Rieger, B. P., Barrett, A., \& Sparks, R. (1994). Assessing multicultural counseling competence: A review of instrumentation. Journal of Counseling \& Development, 72, 316-322.

Sabnani, H. B., Ponterotto, J. G., \& Borodovsky, L. G. (1991). White racial identity development and cross-cultural counselor training: A stage model. The Counseling Psychologist, 19, 76-102.

Sodowsky, G. R. Taffe, R. C., \& Gutkin, T. B. (1991, August). Development and applications of the multicultural counseling inventory. Paper presented at the Annual Convention of the American Psychological Association, San Francisco, CA.

Sue, D. W. (1991). A conceptual model for cultural diversity training. Journal of Counseling \& Development, 70, 99-105.

Sue, D. W., Arredondo, P., \& McDavis, R. J. (1992). Multicultural counseling competencies and standards: A call to the profession. Journal of Counscling \& Development, $70,477-486$.

S. Bureau of the Census (1992). Census of population and housing summary (Tape File IC] [CD-ROM]. Washington, DC: Government Printing Office

Whitfield, D. (1994). Toward an integrated approach to improving multicultural counselor education. Journal of Multicultural Counseling and Development, 22, 239-252.

\section{APAENOIX}

\section{Survey Items}

1. I can discuss my own ethnic/cultural heritage.

2. I am aware of how my cultural background and experiences have influenced my attitudes about psychological processes.

3. I am able to discuss how my culture has influenced the way I think.
4. I can recognize when my attitudes, beliefs, and values are interfering with providing the best services of my clients.

5. I verbally communicate my acceptance of culturally different clientsi.

6. I nonverbally communicate my acceptance of culturally different clients.

7. I can discuss my family's perspective regarding acceptable and nonacceptable codes of conduct.

8. I can discuss models of White identity development.

9. I can define racism.

10. I can define prejudice.

11. I can define discrimination.

12. I can define stereotype.

13. I can identify the cultural bases of my communication style.

14. I can identify my negative and positive emotional reactions toward persons of other racial and ethnic groups.

15. I can identify my reactions that are based on stereotypical beliefs about different ethnic groups.

16. I can give examples of how stereotypical beliefs about culturally different persons impact the counseling relationship.

17. I can articulate the possible differences between the nonverbal behavior of the five major ethnic groups (i.e., African/Black, Hispanic/Latino, Asian, Native American, European/White).

18. I can articulate the possible differences between the verbal behavior of the five major ethnic groups (i.e., African/Black, European/White, Hispanic, Asian, Native American].

19. I can discuss the counseling implications for at least two models of "Minority Identity Development."

20. 1 can discuss within-group differences among ethnic groups (e.g., low socioeconomic status [SES] P u er to Rican client vs. high SES Puerto Rican client].

21. I can discuss how culture affects a client's vocational choices.

22. I can discuss how culture affects the help seeking behaviors of clients.

23. I can discuss how culture affects the manifestation of psychological disorders.

24. I can describe the degree to which a counseling approach is approach is appropriate for a specific group of people.

25. I can explain how factors such as poverty, and powerlessness have influenced the current conditions of at least two ethnic groups.

26. I can discuss research regarding mental health issues and culturally different populations.

27 . I can discuss how the counseling process may conflict with the cultural values of at least two ethnic groups.

28. I can list at least three barriers that prevent ethnic minorities from using mental health services.

29. I can discuss the potential bias of two assessment 
instruments frequently used in the counseling process.

30. I can discuss family therapy from a cultural/ethnic perspective.
31. I can anticipate when my helping style is inappropriate for aculturally different client.

32. I can help clients determine whether a problem stems from racism or biases in others. 